\title{
Forecasting the Stock Market through Dart Board Theory
}

\author{
Faiz Muhammad Shaikh \\ Assistant Professor, SZABAC-Dokri-Larkana \\ E-mail:faianmy2000@hotmail.com \\ Professor Dr. Abdul Latif \\ Chairman Department of Management Sciences \\ Islamia University Bahawalpur \\ E-mail: drabdullatif@hotmail.com
}

Dr.Anwar Ali Shah

Dean, Faculty of Commerce \& Business Administration

University of Sindh-Jamshoro

Muhammad Suhail Nazar

Assistant Professor, Department of Management Sciences

Islamic University Bahawalpur

E-mail:Suhail_nazar@yahoo.com

Received: November10, 2010

Accepted: January 13, 2011

doi:10.5539/ijef.v3n4p106

\begin{abstract}
This research instigates the forecasting the Stock by using the Dart Board theory which is one of the famous theories of them is "Dart Board Theory of Stock Selection": you can select a stock by throwing a dart at the Wall Street Journal and probability of your success is more than others who follow expert's advice. This paper evaluates that significant factor behind the success of dart board theory is Chain Reaction in stock's prices. The data of 30 stocks selected from KSE 100 index (stocks cover about 50-60 percent of total market volume) is arranged in four sub-categories according to their weights assigned in KSE 100 index respectively. The stock's price moves are measured in percentage and arranged from single day to four months Result indicate that Cat: I stocks have dominant effect on stocks' prices of Cat: II and III and causes them to move along. The value of pros/expert recommendation is also measured, based on comparative analysis of change in mutual funds earning with change in average KSE 100 index. Results also support chain reaction concept; as positive correlation exist between performance of KSE 100 index and mutual funds earnings. Findings also indicate that pros recommendations are keys to start a chain reaction.
\end{abstract}

Keywords: Forecasting, Dart board theory, Chain reaction, KSE (Karachi Stock Exchange) 100 index

\section{Introduction}

In an efficient market the prices of securities instantly and fully reflect all availed information and preempt investors from earning abnormal returns. The Performance Of Stocks: Professional Versus Dartboard Picks In an efficient market the prices of securities instantaneously and fully reflect all available information and this preempts investors from earning abnormal returns. In the absence of abnormal returns, investors have no strong incentive to acquire information and a random selection of securities is just as effective as the selection based on extensive security analysis. Therefore the value of information in the form of investment advice has been the subject of discussion and empirical investigation for many years. Several studies have examined the stock price reaction to announcements of investment advice. Examples of investment advice that have been empirically examined include the low cost financial publications such as the "Heard on the Street" column in the Wall Street Journal (see Lloyd-Davies and Canes [21], Liu et.al. [19],[20]); subscription financial newsletters such as the Value Line Investment Survey (see Shelton [24], Hausman [14], Black [2], Holloway [15], Copeland and Mayers [8], Stickel [25], Huberman and 
Kandel [16], Pawlukiewicz and Preece [22]); brokerage house recommendations (see Bjerring et.al. [4]) and other announcements of credit rating changes by rating agencies (see Ingram et.al. [17], Stickel [26]). These studies generally indicate that security analysts have private information not revealed in stock prices. In other words, investment advice has economic value (at least in the short term), and when revealed, results in statistically reliable price changes. These price changes create an opportunity for arbitrage and as such are considered a violation of market efficiency. The purpose of this paper is to test whether the market professionals (also called pros), are any better than naïve investors when it comes to picking stocks. Here the naive investor is assumed to select stocks at random. We thus contribute to the existing debate concerning the value of investment analysts' advice by comparing the performance of a set of stocks selected on professional advice (also called pros picks) with random picks. We look at the public announcements of pros and random picks from the "Investment Dartboard" (ID) column that appears monthly in the Wall Street Journal (WSJ). This approach, therefore, enables us to gauge the effect of pros recommendations on firms' stock prices before, during and after the period in which the announcement first appears in the financial press. This is important, since any unusual behavior pattern in stock prices prior to the publication might stimulate speculation on part of the professional stock pickers. Also because of the publicity effect, the stocks bought or sold on the advice of professionals might outperform the random portfolio only in the short-run. The investment pros could make use of this publicity phenomenon to their advantage by recommending stocks in which they have a vested interest. Therefore, in recognition of the above problem, we compare the performance of the portfolios by holding them for varying periods ranging from approximately a week to six months. This will provide evidence of whether the effect of recommendations in the long-run is transitory or permanent. In the following sections the methodology and the data are described. The fourth section analyses the results and presents our findings and interpretations, while the conclusions are made in the last section.

\section{Methodology}

We compare the performance of the pros and the dart picks by examining whether excess returns (or above-market performance) is realized by buying and holding either of the two portfolios for varying periods of time. The portfolios specifically are held for 5, 21, 42, 84 and 125 trading days. These trading days approximately correspond to 1 week, 1 month, 2 months, 4 months and 6 months respectively. We choose a relatively long holding period for two reasons. First, this lets us compare the performance of the two portfolios purged of any publicity effect that may be present in the securities picked by market analysts. Second, this allows us to examine whether the stock price performance of pros picks are transitory. Moreover, as Pound and Zeckhauser [23] posit, investment professionals have long maintained that their strategies are not supposed to "outsmart" the market over the 30-40 day period typically employed in the event study literature, but rather on a longer-term approach. This has been particularly true for those who attempt to identify undervalued firms. Over the holding periods, we measure the performance of the two portfolios using the cumulative excess returns from the market model (see Brown and Warner [6]).

\section{Equation 1}

Rit $=i+i R m t+$ eit

where:

Rit $=$ return on the common stock of firm $\mathrm{i}$ on day $\mathrm{t}$

$\mathrm{Rmt}=$ return on the equally weighted CRSP index on day $\mathrm{t}$

i, $\quad i=$ regression coefficients

eit $=$ error term for firm $\mathrm{i}$ on day $\mathrm{t}$

For each sample observation, calendar time is converted to event time by defining the date of publication in the WSJ as event day 0 . We first estimate the coefficients of the market model for each firm using daily observations of returns for the 250 trading days spanning the period -375 through -126 . Days -125 to +125 are set aside as the event window in which short-term as well as long-term abnormal returns are to be studied. For each firm i, prediction errors, PEit, are calculated for each day in the analysis period,

\section{Equation 2}

PEit $=$ Rit $-(a i+b i R m t)$

Where ai and bi are estimates of $i$ and $\quad I$

\subsection{DATA}

Investment Dartboard Column (ID) 
The "ID" column was created in October 1988 by John R. Dorfman and is henceforth being published in the first half of every month in the Wall Street Journal. This column was designed by pitting professional stock pickers against dart throwing amateurs. In this 'game' a quartet of well-regarded investment experts pick their favorite stock to either buy or sell, while four amateurs hurl darts at a list of New York Stock Exchange (NYSE) or Over-theCounter (OTC) stocks and record the names of the stocks pierced by pure chance. The column then publishes the performance (unadjusted for market risk) of each of the portfolios in the subsequent month. The pros whose selections do best are invited back in the next month for another round of a similar game. The motive behind initiating this column was to see if the professional investor with all his/her sophistication in the form of superior judgment, information and analysis can outperform the relatively uninformed, naive investor.

\subsection{Sample}

We examined this column on a monthly basis from October 2000 through June 2009 For the stocks to enter into our sample, they had to meet the following criteria:

\section{The firms had to be listed on the KSE (Karachi Stock Exchange) market.}

2. The stocks must be traded for 375 days prior to and 125 days subsequent to the day of publication. A total of 132 recommendations were made by the pros during the sample period, of which 114 were buy recommendations. 2 Twelve (12) of these stocks fail to meet the above selection criteria and thus the pros portfolio consists of 120 stocks. The sample of random stocks is also obtained from the "Investment Dartboard Column" in the.

\section{Results}

\section{Short-Term Stock Price Response}

In this section, the short-term stock price response surrounding the pros recommendation is examined. The abnormal returns and the associated t-statistics for days -10 through day +10 are presented in Table 1 . It can be seen that the abnormal return on the day of announcement is 2.87 percent and is highly significant at any conventional level. The post announcement period provides evidence that day +1 abnormal return is 0.80 percent and is also significant. Other than this, all of the post announcement returns except for day +4 are insignificant. These results are similar to the findings of Liu et.al. [19] in their examination of the stock price reaction to the securities recommendation on the 'Heard on the Street' column and also analyze the cumulative prediction errors (CAPE) over a set of different short intervals given by $(-1,+1),(-$

$2,+2),(-5,+5),(0,+1),(0,+2),(0,+3),(1,+2)$ and $(1,+5)$. This is shown in Table 2 . The results indicate that the pros picks generate significant abnormal returns over all the short intervals that are inclusive of the event day. The highest statistically significant abnormal return is found during the interval $(0,+1)$ which represents a 3.66 percent abnormal return. Overall, the results support the hypothesis that investors earn positive abnormal returns surrounding the date of the pros recommendation.

\section{Random Picks}

Table 1 and Table 2 also present the day -10 through day +10 excess returns and the cumulative excess returns over different short intervals for the random picks. True by nature of the inherent selection process, the results show that the stock prices behave randomly, with none of the returns being significantly abnormal. The interval statistics show no sign of significance. It can be therefore said that the pros portfolio exhibit larger excess returns than the portfolio picked on random by a naive investor in the short-run. But it remains to be seen if the pros can "outsmart" this naive investor over a relatively longer interval.

\subsection{Response Over Longer Intervals}

To determine whether the pros recommendation has a permanent effect on stock returns, longer intervals following the recommendation are examined. The intervals include $(0,+21),(0,+42),(0,+84)$ and $(+0,+125)$. These intervals approximately correspond to 1 month, 2 months, 4 months and 6 months respectively.

As seen in Table 3, the pros portfolio does not generate any significant excess returns for holding periods of one month and two months. Furthermore, it is observed that the excess returns become significantly negative if the portfolio recommended by the pros is held for four and six months. On the other hand, not surprisingly, the portfolio comprised of random picks shows insignificant abnormal holding period returns over all the intervals.

\subsection{Differences In Market Response}

In the previous sections, we report that significantly positive abnormal returns are associated with the pros portfolio in the short-run but not in the long-run. In this section, tests of significance are performed to determine whether there is a difference in the magnitude of the response between the two portfolios in the short- and long-run. This is 
done by testing the mean difference between the cumulative average prediction error of the two portfolios for each interval. To test the differences in price response over particular intervals, the following test statistic is used:

Equation 6

t CAPE CAPE ST Td . 12 )/

where CAPE1T and CAPE2T are the mean cumulative average prediction error (abnormal return) over interval $\mathrm{T}$ for the pros and random portfolios respectively; and $\mathrm{Sd}$ is an estimate of the standard deviation of the difference appearing in the numerator. Sd is calculated as the square root of the following3:

\section{Equation 7}

\section{$\operatorname{sis} n d 2122$. (2)/}

where $\mathrm{n}$ is equal to 120 and is the size of the pros or random portfolio, and s1 2 and s2 2 are the variances of the CAPEs for the pros selection and random picks respectively. The test results over various intervals are presented in Table 4 . The results presented include tests that are conducted for the intervals $(0,+5),(0,+21),(0,+42),(0,+84)$ and $(0,+125)$. Examination of the results indicate that the mean excess return of the pros portfolio is significantly higher only in the shortest of intervals considered, i.e., $(0,+5)$. This difference in excess returns between the two portfolios then gradually decreases with increasing intervals and ends up being significantly negative. This implies that the random portfolio outperforms the pros portfolio when the holding period is six months. The implication of these tests are that the pros recommendations, in comparison to the random picks, "pay off" only when the investor buys (or sells) the stock before the pros recommendation becomes public and holds the stock for a very short period. Thus a publicity effect from the recommendation is discerned, which is indicative of a moral hazard problem, in that the pros have an incentive to recommend stocks in which they have a vested interest in. However, this publicity effect does not last long as the positive abnormal performance of the pros picks is found to be transitory. The results found are also consistent with the overreaction literature (see for example De Bondt and Thaler [9], Brown,

Harlow and Tinic [5], Atkins and Dyl [1], Chopra et.al.[7], Liang and Mullineaux [18]). The overreaction hypothesis claims that investors systematically overreact to extreme events and place too much emphasis on relatively recent information. This leads to a correction or a price reversal in stock prices in the post event period. Our findings corroborate this hypothesis, in that the positive stock price reaction to pros recommendation is followed by a gradual reversal in stock prices.

The observed phenomenon, short-term positive reaction and long-term negative reaction, is reminiscent of the noise trading hypothesis proposed by Black [3], De Long et.al. [10], [11] and Froot et.al. [12]. Under this hypothesis, the pricing errors induced by noise trading (i.e. trading by uninformed investors) are eventually reversed. Our results support such a case.

\section{Conclusion}

We examine the value of investment advice given monthly by investment analysts in the "Investment Dartboard Column". The portfolio thus formed is compared with another portfolio which consists of stocks selected at random. The results indicate that the pros portfolio generates significant positive abnormal return on the day of publication in the WSJ. However, upon comparison of this portfolio with the dart portfolio, the pros portfolio outperforms the dart portfolio only when the holding period is one week or less. For holding periods longer than a week, the pros portfolio does not perform better than the portfolio of random picks.

\section{References}

Atkeson, A., \& Kehoe, P. J. (1999). Models of Energy Use: Putty-Putty versus Putty-Clay. American Economic Review, 89(4), 1043. doi:10.1257/aer.89.4.1028, http://dx.doi.org/10.1257/aer.89.4.1028

Backus, D. K., \& Crucini, M. J. (2000). Oil prices and the terms of trade. Journal of International Economics, 50(1), 213. doi:10.1016/S0022-1996(98)00064-6, http://dx.doi.org/10.1016/S0022-1996(98)00064-6

Barsky, R. B., \& Kilian, L. (2001). Do We Really Know that Oil Caused the Great Stagflation? A Monetary Alternative. NBER/Macroeconomics Annual, 16(1), 137-183. doi:10.1162/088933601320224900, http://dx.doi.org/10.1162/088933601320224900

Bernanke, B. S., Gertler, M., \& Watson, M. (1997). Systematic Monetary Policy and the Effects of Oil Price Shocks. Brookings Papers on Economic Activity(1), 157.

Berndt, E. R., \& Wood, D. O. (1979). Engineering and Econometric Interpretations of Energy-Capital Complementarity. American Economic Review, 69(3), 354.

Bryan, M. F. (2002). Is It More Expensive, or Does It Just Cost More Money? Economic Commentary. 
Burbridge, J., \& Harrison, A. (1984). Testing For the Effects of Oil--Price Rises Using Vector Autoregressions. International Economic Review, 25(2).

Chang, E. C., \& Cheng, J. W. (2000). Further evidence on the variability of inflation and relative price variability. Economics $\quad$ Letters, 66(1), 71-77. doi:10.1016/S0165-1765(99)00186-X, http://dx.doi.org/10.1016/S0165-1765(99)00186-X

Chang, Y., \& Wong, J. F. (2003). Oil price fluctuations and Singapore economy. Energy Policy, 31(11), 1151-1165. doi:10.1016/S0301-4215(02)00212-4, http://dx.doi.org/10.1016/S0301-4215(02)00212-4

Cooper, J. C. B. (2003). Price elasticity of demand for crude oil: estimates for 23 countries. OPEC Review: Energy Economics \& Related Issues, 27(1), 8.

Crook, C. (2006). Shock Absorption. Atlantic Monthly (1072-7825), 297(5), 32-32.

Cunado, J., \& Perez de Gracia, F. (2005). Oil prices, economic activity and inflation: evidence for some Asian countries. The Quarterly Review of Economics and Finance, 45(1), 65-83. doi:10.1016/j.qref.2004.02.003, http://dx.doi.org/10.1016/j.qref.2004.02.003

Darby, M. R. (1982). The Price of Oil and World Inflation and Recession. 28American Economic Review, 72(4).

Davis, S. J., \& Haltiwanger, J. (2001). Sectoral job creation and destruction responses to oil price changes. Journal of Monetary Economics, 48(3), 465-512. doi:10.1016/S0304-3932(01)00086-1, http://dx.doi.org/10.1016/S0304-3932(01)00086-1

Davis, S. J., Prakash, L., \& Ramamohan, M. (1996). Regional Labor Fluctuations: Oil Shocks, Military Spending, and Other Driving Forces: University of Chicago.

de Miguel, C., \& Manzano, B. (2006). Optimal oil taxation in a small open economy. Review of Economic Dynamics, 9(3), 438-454. doi:10.1016/j.red.2005.10.004. http://dx.doi.org/10.1016/j.red.2005.10.004

Doroodian, K., \& Boyd, R. (2003). The linkage between oil price shocks and economic growth with inflation in the presence of technological advances: a CGE model. Energy Policy, 31(10), 989-1006. doi:10.1016/S0301-4215(02)00141-6, http://dx.doi.org/10.1016/S0301-4215(02)00141-6

Fisher, E. O. N., \& Marshall, K. G. (2006). The Anatomy of an Oil Price Shock: Federal Reserve Bank of Cleveland.

\section{Appendix}

\begin{tabular}{|lllll|}
\hline & AVERAGES & & & \\
& CAT-I & CAT-II & CAT-III & CAT-IV \\
Mon, Jan 02, 2006 & 1.15 & 1.68 & 1.32 & 2.14 \\
Tue, Jan 03, 2006 & 0.66 & 0.83 & 0.85 & 2.02 \\
Wed, Jan 04, 2006 & 1.97 & 0.28 & 0.35 & -1.02 \\
Thu, Jan 05, 2006 & 1.21 & 1.36 & 0.61 & 2.12 \\
Fri, Jan 06, 2006 & 0.45 & 0.14 & -0.94 & -2.13 \\
Mon, Jan 09, 2006 & 1.31 & 1.57 & 0.15 & 0.26 \\
Mon, Jan 16, 2006 & 0.83 & 1.95 & 1.77 & -0.05 \\
Tue, Jan 17, 2006 & 0.79 & 2.44 & 0.85 & -0.39 \\
Wed, Jan 18, 2006 & 0.33 & 0.65 & -0.16 & -0.20 \\
Thu, Jan 19, 2006 & 0.80 & 1.90 & 1.02 & 4.40 \\
Fri, Jan 20, 2006 & -0.26 & 0.82 & 0.07 & 3.50 \\
Mon, Jan 23, 2006 & 1.19 & 0.65 & 1.51 & 2.42 \\
Tue, Jan 24, 2006 & -2.40 & -2.78 & -3.39 & -2.61 \\
Wed, Jan 25, 2006 & -0.19 & 0.14 & -0.10 & 2.72 \\
Thu, Jan 26, 2006 & 0.75 & -0.62 & 1.36 & 3.85 \\
Fri, Jan 27, 2006 & 1.15 & 4.20 & 1.25 & 2.62 \\
Mon, Jan 30, 2006 & 1.14 & 0.65 & 0.77 & 2.48 \\
Tue, Jan 31, 2006 & -0.56 & -0.21 & -0.69 & -0.29 \\
Wed, Feb 01, 2006 & -0.51 & 0.32 & -0.08 & -0.48 \\
Thu, Feb 02, 2006 & -0.07 & -0.40 & 0.76 & 3.30 \\
Fri, Feb 03, 2006 & 2.17 & 2.03 & 2.07 & 2.37 \\
Mon, Feb 06, 2006 & 0.30 & 0.10 & 0.95 & 4.19 \\
Tue, Feb 07, 2006 & 0.88 & 0.44 & -0.08 & 1.03 \\
Fri, Feb 10, 2006 & 0.18 & 0.98 & 0.52 & -1.97 \\
Mon, Feb 13, 2006 & 0.91 & -0.04 & 0.75 & -1.75 \\
\hline
\end{tabular}




\begin{tabular}{|c|c|c|c|c|}
\hline Tue, Feb 14, 2006 & -1.59 & -2.79 & -2.71 & -1.30 \\
\hline Wed, Feb 15, 2006 & 3.18 & 1.54 & 1.60 & 4.35 \\
\hline Thu, Feb 16, 2006 & -0.46 & -1.01 & -0.94 & 0.94 \\
\hline Fri, Feb 17, 2006 & 1.43 & 1.04 & 0.36 & 0.34 \\
\hline Mon, Feb 20, 2006 & 1.45 & 1.60 & 0.35 & -1.60 \\
\hline Tue, Feb 21, 2006 & 0.54 & 1.50 & -0.27 & -0.90 \\
\hline Wed, Feb 22, 2006 & -0.46 & 0.54 & 0.14 & -1.62 \\
\hline Thu, Feb 23, 2006 & 0.90 & 1.57 & -0.07 & -0.96 \\
\hline Fri, Feb 24, 2006 & 0.19 & -1.15 & -1.42 & -2.15 \\
\hline Mon, Feb 27, 2006 & -2.20 & -1.84 & -3.29 & -5.44 \\
\hline Tue, Feb 28, 2006 & 1.89 & 2.28 & 0.69 & 1.64 \\
\hline Wed, Mar 01, 2006 & -0.19 & 0.74 & -1.26 & 1.87 \\
\hline Thu, Mar 02, 2006 & -1.19 & -0.50 & 0.23 & 0.44 \\
\hline Fri, Mar 03, 2006 & 0.16 & 1.43 & 1.14 & 0.27 \\
\hline Mon, Mar 06, 2006 & -4.76 & -2.27 & -5.56 & -5.45 \\
\hline Tue, Mar 07, 2006 & 0.99 & 1.81 & -0.52 & 0.94 \\
\hline Wed, Mar 08, 2006 & -4.71 & -3.30 & -3.75 & -5.30 \\
\hline Thu, Mar 09, 2006 & 1.58 & 1.50 & 1.86 & 3.14 \\
\hline Fri, Mar 10, 2006 & -3.09 & -2.65 & -2.18 & -2.75 \\
\hline Mon, Mar 13, 2006 & -4.42 & -2.85 & -3.11 & -4.96 \\
\hline Tue, Mar 14, 2006 & 3.17 & 1.49 & 2.13 & 4.74 \\
\hline Wed, Mar 15, 2006 & -0.36 & 0.14 & 0.29 & 0.36 \\
\hline Thu, Mar 16, 2006 & 2.61 & 2.36 & 2.32 & 1.98 \\
\hline Fri, Mar 17, 2006 & 2.69 & 2.42 & 1.18 & 1.15 \\
\hline Mon, Mar 20, 2006 & 0.20 & 0.85 & 0.98 & -0.54 \\
\hline Tue, Mar 21, 2006 & -0.78 & -1.90 & 0.44 & 0.38 \\
\hline Wed, Mar 22, 2006 & 0.32 & 0.93 & -3.03 & 1.54 \\
\hline Fri, Mar 24, 2006 & 0.84 & 1.11 & 0.12 & -0.41 \\
\hline Mon, Mar 27, 2006 & -0.36 & -0.13 & 0.05 & -1.25 \\
\hline Tue, Mar 28, 2006 & 0.21 & 1.06 & 1.03 & 1.62 \\
\hline Wed, Mar 29, 2006 & 0.46 & 0.38 & 0.27 & -0.91 \\
\hline Thu, Mar 30, 2006 & 1.02 & 1.12 & 1.03 & -0.63 \\
\hline Fri, Mar 31, 2006 & 0.22 & 1.54 & -0.20 & -1.60 \\
\hline Mon, Apr 03, 2006 & 1.53 & 1.34 & 0.75 & 1.34 \\
\hline Tue, Apr 04, 2006 & 0.94 & 0.86 & 1.42 & 4.04 \\
\hline Wed, Apr 05, 2006 & 0.77 & 1.51 & 0.93 & 1.19 \\
\hline Thu, Apr 06, 2006 & 0.20 & 0.68 & 0.28 & 0.01 \\
\hline Fri, Apr 07, 2006 & 2.42 & 2.82 & 0.74 & -1.52 \\
\hline Mon, Apr 10, 2006 & 0.39 & 1.40 & 0.19 & -1.34 \\
\hline Thu, Apr 13, 2006 & -0.20 & 0.98 & 0.11 & 0.54 \\
\hline Fri, Apr 14, 2006 & 1.17 & -1.03 & -0.12 & -0.49 \\
\hline Mon, Apr 17, 2006 & -0.45 & -1.61 & -0.22 & -1.50 \\
\hline Tue, Apr 18, 2006 & -1.21 & -1.45 & -0.42 & -1.40 \\
\hline Wed, Apr 19, 2006 & -0.75 & -0.44 & -0.68 & -1.40 \\
\hline Fri, Apr 21, 2006 & -2.10 & -0.52 & -0.30 & 1.15 \\
\hline Mon, Apr 24, 2006 & -1.96 & -2.20 & -3.25 & -1.81 \\
\hline Tue, Apr 25, 2006 & 0.93 & -0.28 & 0.91 & 0.74 \\
\hline Wed, Apr 26, 2006 & -0.02 & -0.87 & -0.53 & -0.62 \\
\hline Thu, Apr 27, 2006 & -1.93 & -1.79 & -2.51 & -1.88 \\
\hline Fri, Apr 28, 2006 & -3.43 & -2.77 & -1.98 & -4.46 \\
\hline
\end{tabular}


Table 2.

\begin{tabular}{|c|c|c|c|}
\hline \multicolumn{4}{|l|}{ SD } \\
\hline CAT-I & CAT-II & CAT-III & CAT-IV \\
\hline 1.11 & 2.024387 & 0.948937 & 2.606168 \\
\hline 1.11 & 0.944966 & 0.918019 & 4.708147 \\
\hline 1.67 & 1.821347 & 2.163143 & 1.557214 \\
\hline 1.48 & 1.726363 & 1.59281 & 1.88549 \\
\hline 2.08 & 2.484764 & 0.626735 & 0.994573 \\
\hline 1.53 & 1.959841 & 0.729719 & 1.235059 \\
\hline 1.22 & 2.246323 & 2.097321 & 1.070572 \\
\hline 1.52 & 2.250239 & 1.4162 & 1.540062 \\
\hline 2.11 & 2.090357 & 1.335522 & 2.203604 \\
\hline 1.95 & 2.680775 & 1.257179 & 3.338071 \\
\hline 1.87 & 2.876586 & 2.274705 & 3.490435 \\
\hline 1.86 & 2.405836 & 2.134294 & 2.461422 \\
\hline 1.50 & 1.786826 & 1.710521 & 3.428861 \\
\hline 2.11 & 0.841696 & 1.639729 & 4.044069 \\
\hline 1.47 & 7.324706 & 1.354526 & 2.453531 \\
\hline 1.38 & 9.51008 & 1.575287 & 3.587981 \\
\hline 1.67 & 1.921991 & 0.796582 & 3.387416 \\
\hline 2.64 & 2.199972 & 0.86341 & 2.254661 \\
\hline 2.18 & 2.234754 & 0.938872 & 1.064679 \\
\hline 2.18 & 1.772767 & 1.654629 & 1.846235 \\
\hline 2.37 & 2.004685 & 1.17447 & 2.589076 \\
\hline 1.34 & 2.096222 & 1.988813 & 3.943624 \\
\hline 1.77 & 2.712487 & 1.743054 & 0.661553 \\
\hline 2.07 & 2.821275 & 2.118217 & 3.103055 \\
\hline 2.02 & 2.657928 & 2.228671 & 2.293384 \\
\hline 2.64 & 1.740731 & 2.717922 & 1.515893 \\
\hline 1.74 & 2.344712 & 1.291354 & 2.232423 \\
\hline 2.05 & 2.620557 & 1.431719 & 1.760412 \\
\hline 1.96 & 1.847314 & 2.16834 & 1.727173 \\
\hline 2.61 & 2.258835 & 3.63599 & 1.239938 \\
\hline 2.05 & 2.8639 & 2.67218 & 1.259545 \\
\hline 2.68 & 2.492051 & 2.13775 & 1.795901 \\
\hline 2.61 & 2.167663 & 1.692926 & 1.306659 \\
\hline 2.15 & 1.815773 & 1.491838 & 2.021255 \\
\hline 2.94 & 2.434956 & 1.250537 & 2.066244 \\
\hline 1.91 & 2.64971 & 3.868821 & 6.155052 \\
\hline 2.22 & 1.5172 & 3.408915 & 5.453468 \\
\hline 2.06 & 1.915834 & 1.881097 & 1.475929 \\
\hline 1.81 & 2.309959 & 1.789309 & 1.569034 \\
\hline 0.93 & 3.532152 & 4.258813 & 2.113064 \\
\hline 2.17 & 2.101564 & 3.503646 & 2.881934 \\
\hline 0.75 & 2.72704 & 2.505971 & 1.991597 \\
\hline 1.87 & 2.834956 & 2.63941 & 2.525401 \\
\hline 2.12 & 2.900715 & 2.871218 & 1.951071 \\
\hline 0.99 & 2.232281 & 2.478933 & 1.77646 \\
\hline 1.77 & 6.967463 & 2.62805 & 1.594397 \\
\hline 2.03 & 4.730147 & 2.576135 & 2.942637 \\
\hline 2.17 & 1.708812 & 1.376185 & 2.452829 \\
\hline 1.96 & 2.101591 & 2.702407 & 2.58259 \\
\hline 4.36 & 2.132302 & 2.227531 & 0.973874 \\
\hline 3.52 & 7.201807 & 1.903318 & 2.805916 \\
\hline 1.68 & 1.687182 & 8.306571 & 2.407248 \\
\hline 2.22 & 2.139395 & 1.802499 & 1.692868 \\
\hline 1.96 & 2.994183 & 1.837547 & 1.223077 \\
\hline 0.93 & 1.891391 & 1.622962 & 2.036478 \\
\hline 1.71 & 1.559208 & 1.702685 & 1.00114 \\
\hline 1.65 & 1.936535 & 1.833887 & 0.49573 \\
\hline 1.83 & 2.420411 & 1.402405 & 1.248984 \\
\hline 1.85 & 2.152643 & 1.848998 & 2.586683 \\
\hline 1.43 & 1.588251 & 1.792153 & 4.165207 \\
\hline 1.79 & 2.177357 & 2.579449 & 1.833274 \\
\hline 2.13 & 2.408632 & 2.54481 & 1.237197 \\
\hline 1.77 & 1.701212 & 1.489277 & 1.570343 \\
\hline 1.79 & 2.323453 & 1.72673 & 1.650219 \\
\hline 1.42 & 3.450976 & 1.969413 & 2.146119 \\
\hline 2.15 & 2.759584 & 2.67725 & 1.497285 \\
\hline 4.53 & 4.165588 & 2.435589 & 0.926789 \\
\hline 1.82 & 1.973939 & 2.516828 & 1.893565 \\
\hline 1.24 & 2.367482 & 1.74778 & 2.867596 \\
\hline 3.51 & 2.450209 & 2.595089 & 3.346337 \\
\hline 1.32 & 1.81861 & 1.88271 & 2.147224 \\
\hline 2.11 & 2.528644 & 2.521171 & 1.841011 \\
\hline 1.72 & 2.873136 & 0.99042 & 0.83613 \\
\hline 1.31 & 3.639456 & 1.551302 & 0.676324 \\
\hline 1.34 & 2.506209 & 2.853335 & 1.56913 \\
\hline
\end{tabular}

